\title{
Modelagem de Consumo de Combustível de um Veículo Sujeito a Trânsito usando Sistemas com Saltos Markovianos
}

\author{
Diogo Henrique de Melo ${ }^{1}$
}

Departamento de Ciência da Computação e Matemática Computacional, USP, São Carlos, SP Eduardo Fontoura Costa ${ }^{2}$

Departamento de Ciência da Computação e Matemática Computacional, USP, São Carlos, SP

Resumo. Este trabalho aborda um modelo que busca otimizar o consumo de um veículo ao longo de um percurso sujeito a trânsito. O modelo do veículo utiliza um sistema com saltos Markovianos e parâmetros de fácil ajuste, como curva de potência e massa.

Palavras-chave: modelagem, otimização, sistemas Markovianos, modelos estocásticos.

\section{Introdução}

O problema de minimização de consumo de energia na operação de um veículo é claramente importante, pois além de aspectos econômicos, é de relevância social e ambiental. Uma abordagem interessante refere-se a minimização do consumo aproveitando o gerenciamento das energias potencial gravitacional e cinética ao longo de um percurso. Essa abordagem foi tratada por [1], levando em conta um modelo relativamente simples para representar o deslocamento do veículo, permitindo o levantamento de parâmetros de forma rápida e eficiente, enquanto outras abordagens utilizam, por exemplo, complexas equações termodinâmicas [2], dificultando alguns ajustes. O modelo de [1] é descrito por

$$
\begin{aligned}
& x_{k+1}=x_{k}+v_{k} \Delta t \\
& v_{k+1}=\sqrt{v_{k}^{2}-2 g \Delta h_{k}+2 \Delta t\left(\frac{P\left(v_{k}, u_{k}\right)-c_{2} v_{k}^{2}}{m}\right)},
\end{aligned}
$$

sendo que as variáveis de estado $x_{k}$ e $v_{k}$ representam posição e velocidade do veículo em um instante discretizado $t=k \Delta_{t}$, sendo $\Delta_{t}$ o período amostral, $u_{k}$ é a entrada de controle representando o fluxo de combustível entrando no motor, com $0 \leq u \leq 1$, a função $h(x)$ descreve a altitude do veículo em um ponto $x$ sendo $\Delta h_{k}$ a variação de altitude nos instantes $k$ e $k+1$ e $g$ a aceleração da gravidade. A função $P\left(v_{k}, u_{k}\right)$ descreve a potência

\footnotetext{
${ }^{1}$ diogo_melo@usp.br

2 efcosta@icmc.usp.br
} 
fornecida ou absorvida pelo motor em função da velocidade $v$ e do controle $u$. O total de combustível utilizado no intervalo de tempo $[0 ; T]$ é escrito simplesmente por $\sum_{k=0}^{T} u_{k} \Delta t$.

Contudo, o modelo acima desconsidera efeitos de perturbação que incidem na implementação da solução ótima, principalmente por trânsito de outros veículos, que pode ser representado por eventos aleatórios de redução de velocidade.

\section{Métodos}

Esses eventos intervenientes decorrentes da inserção de trânsito serão modelados por cadeias de Markov, levando um modelo com saltos markovianos na forma

$$
v_{k}=a_{r(k)} \sqrt{v_{k}^{2}-2 g \Delta h_{k}+2 \Delta t\left(\frac{P\left(v_{k}, u_{k}\right)-c_{2} v_{k}^{2}}{m}\right)},
$$

em que $r(k)$ é o estado de uma cadeia de Markov assumindo valores em um conjunto finito $S$, e $a_{i}$ são valores conhecidos para cada $i \in S$, sendo que existe uma probabilidade $p_{i j}$ de migrar do estado $i$ para o estado $j \in S$. Desta maneira teremos $v_{k}$ uma variável aleatória, assim como o consumo de combustível, que pode ser minimizado através da função

$$
\min _{u_{0}, \ldots, u_{T}} E\left\{\sum_{k=0}^{T} u_{k}+q\|x(T)-\bar{x}\|\right\},
$$

em que $\bar{x}$ é a posição desejada para o veículo no instante $T$ (final do percurso) e $q$ é um constante de ponderação.

\section{Resultados e conclusão}

Com o modelo de [1] foi possível obter economia média de $5 \%$ no consumo de combustível utilizando técnicas de otimização baseadas em Programação Dinâmica (PD).

Trabalhos futuros envolverão o levantamento das probabilidades $p_{i j}$ através de simulações, e em seguida resolver o problema de otimização estocástica por PD. Também pretende-se realizar simulações e estudos de caso com a solução obtida, procurando caracterizar os efeitos da inserção do trânsito.

\section{Agradecimentos}

Agradecemos o apoio financeiro da FAPESP via Procs. 2013/19380-8 e 2014/13852-8.

\section{Referências}

[1] P. H. Affonso e E. F. Costa, Otimização de consumo de combustível em percurso de automóvel, CMAC, (2011), Uberlândia:[s.n.] p.1.

[2] L. Guzzella and A. Sciarretta, Vehicle propulsion systems, [S.L.]: Springer, (2007). 